hasty to bind the prospects of the county asylum servants by any resolution at a meeting of that size. (Hear, hear.) It was a little dangerous to devise any scheme. He thought it should be left to the Parliamentary Committee.

Dr. LiND8A Y said it would be a recommendation to the Parliamentary Committee as coming from that meeting. The Civil Service scheme had been threshed out time after time, and there was a very general feeling on the part of medical officers in its favour. It was very generally accepted as the next best thing they were likely to get, or had any chance of getting.

The resolution was agreed to.

It was arranged that the Pensions Committee should be summoned to meet at an early date, and also that a circular should be sent to each member of the Association, stating the steps that had been taken, and asking his opinion on the points referred to.

\title{
ON THE USE OF RESTRAINT IN THE CARE OF THE INSANE.
}

To the Editors of "The Jodrnal or Mental Science."

Gentlemen, - In introducing the discussion on Restraint at our last quarterly meeting in Edinburgh, I used these words, "Restraint when dictated by harshness, irritation, or mere convenience is utterly wrong, but restraint when part of a well-considered plan of treatment, may, in special cases, be perfectly wise and right." This proved to be the unanimous opinion of the meeting; but it does not satisfy my friend Dr. Robertson, who has strangely misread your report of the discussion, and has thought it necessary with mistaken zeal, though I am sure the best motives, to come forth as the uncompromising champion of non-restraint. $\mathrm{He}$ writes to the Journal to express his surprise and sorrow at the errors of his brethren, and avers, in direct opposition to their own words, that they " advocated a return to the use of measures of restraint, whose all but total abolition was the especial glory of Tuke at York and Conolly at Hanwell, and reflected honour on the land of their birth." Under the extraordinary impression that such is the aim and such the practice of his confrères, Dr. Robertson gives many details of his own asylum management in order to show us a more excellent way. These details prove, what no one doubts, that he is an able and efficient Superintendent, but with one exception they are quite irrelevant. The relevant information is that Dr. Robertson uses restraint in surgical cases, uses gloves in highly suicidal cases, and does not regard their use as a violation of the "non-restraint" treatment. Dr. Robertson thus agrees with those who deem restraint justifiable in certain exceptional cases. His own judicious practice is a sufficient reply to his letter, and it is unnecessary to repeat the arguments used at Edinburgh. 
Since Dr. Robertson so misunderstands his own position I can excuse his misapprehension of mine. To learn from his letter that I am "the leader in Scotland of a retrograde movement" and an " advocate of the cause of restraint," to be told that in my opinion "mechanical restraint is required in four classes of cases," and to have the foundation-stone of this asylum metaphorically hurled at my head, was indeed amazing.

My words at Edinburgh were :- "I am no advocate of mechanical restraint, and in ordinary cases regard it as unnecessary and wrong, because not the best thing for the patient. I think it needful only in very exceptional cases, but we can accept no dictation as to its use." Surely no words could be more explicit, or more strangely perverted. My practice agrees therewith. There is no camisole or instrument of mechanical restraint in Gartnavel, and its records show that, excluding gloves, I have used personal restraint in two cases during the last fifteen years, one of them being a surgical case, and in two cases have used a sort of protection-bed which I had to improvise for the occasion. The average number of patients resident during these years has been 512 . With such a record perhaps I need not fear even the foundation-stone!

To give greater emphasis to his condemnation of restraint, Dr. Robertson refers to the bust of Dr. Conolly and quotes the speeches made at its presentation. Here are Dr. Conolly's views as given by his biographer, Sir James Clark (see Memoir, p. 160) :"It is desirable, therefore, that it should be understood that there is no such thing as an absolute repudiation of restraint in the treatment of the insane. The warmest advocates of non-restraint admit that cases may occur in which it is proper to resort to mechanical restraint, and by this admission we do not think that we invalidate the principle, which is not of universal application, though it is made as nearly universal as possible, and is departed from only when the necessity for doing so is clear, and then with regret that there is no better way of attaining the object." Dr. Robertson's letter shows how a too zealous disciple may outrun a wise master.

Restraint used needlessly, or heedlessly, or harshly, cannot be too strongly condemned; it was from such restraint that Conolly and his fellow-workers, to their eternal honour, delivered the insane; but restraint used by a humane and skilful physician with full knowledge, and after full consideration, is in certain rare cases the kindest and the wisest treatment.

$$
\text { Yours faithfully, }
$$

D. YELLOWLEES.

Gartnavel, Glasgow, June, 1889. 